\title{
The triple therapy for chronic obstructive pulmonary disease increases the risk of pneumonias compared to the dual-bronchodilator therapy
}

\author{
Keisuke Watanabe, Nobuyuki Horita, Takeshi Kaneko \\ Department of Pulmonology, Yokohama City University Graduate School of Medicine, Yokohama, Japan \\ Correspondence to: Nobuyuki Horita, MD, PhD. Department of Pulmonology, Yokohama City University Graduate School of Medicine, 3-9 Fukuura, \\ Kanazawa-ku, Yokohama 236-0004, Japan. Email: horitano@yokohama-cu.ac.jp.
}

Submitted May 17, 2020. Accepted for publication Jun 18, 2021.

doi: 10.21037/jtd-20-1955

View this article at: https://dx.doi.org/10.21037/jtd-20-1955

Chronic obstructive pulmonary disease (COPD) became the third leading cause of death in the world in 2020 (1). Two types of long-acting inhaled bronchodilators, namely long-acting muscarinic antagonists (LAMAs) and longacting beta-2-agonists (LABAs), play an essential role in the maintenance treatment of COPD $(1,2)$. Besides, inhaled corticosteroids (ICS) may be administered for a subgroup of COPD cases (1). There was a long-lasting controversy whether ICS is a safe and effective medication for COPD management $(3,4)$. If ICS has indication, which subgroup of COPD patients have reasonable indication for the triple therapy, the combination of LAMA, LABA, and ICS. The GOLD 2020 recommends the triple therapy for patients belonging to the Group D who have eosinophilia because some of recent large-scale randomized controlled trials (RCTs) revealed that the triple therapy greatly reduced the risk of exacerbation of eosinophilic patients (1). In addition, the triple therapy has a reasonable indication for those with asthma COPD overlap (5).

Exacerbation is often used as the primary endpoint of trials that assess the medical treatment for COPD because an expected number of all-cause deaths, an ultimate endpoint, is too small and because an exacerbation has substantial impact on the mortality, quality of life change, and future clinical course of COPD. Besides the exacerbation, a pneumonia is another serious concern to choose inhaled medications for COPD because a pneumonia directly disposes a patient at a high risk of death and critically worsens future clinical course even if survived (6). ICS alone or in combination with a LABA has known to increase the risk of pneumonia $(3,4)$. A recent real-world analysis by Suissa $e t$ al. with nearly nine thousand cases reported that the incidence of severe pneumonia requiring hospitalization was increased with the triple therapy initiation [hazard ratio, 1.46; 95\% confidence interval (CI), 1.03-2.06] (7). Whether the triple therapy increases the risk of pneumonia in RCTs is a serious issue because RCT is the most reliable and standard study design to assess the impact of any medication. Although many trials have been conducted to compare the dual bronchodilator therapy and the triple therapy for COPD, the published articles showed varied results how the triple therapy affect the risk of pneumonia. We conducted a meta-analysis to see if COPD patients who were treated with the triple therapy have increased risk of a pneumonia compared to those with the dual bronchodilator.

Patient informed consent and institutional ethics review board approval were not applicable since our review did not directly deal with patients and clinical data. We tried to search for candidate articles using PubMed, Cochrane CENTRAL, and Web of Science Core Collection on April 20, 2020. Both randomized and well-designed nonRCTs that compared the triple therapy and the dualbronchodilator therapy in any language were included. Withdrawing ICS from the triple therapy was allowed. The patients should be diagnosed to have COPD based on the standard guidelines (1). The primary endpoint of our analysis is the incidence of pneumonia during follow-up. Subgroup analyses from RCTs and observational studies were performed. Data were independently extracted by two review authors $(\mathrm{KW}, \mathrm{NH})$. A random-effect model metaanalysis using Mantel-Haenszel odds ratio was performed 


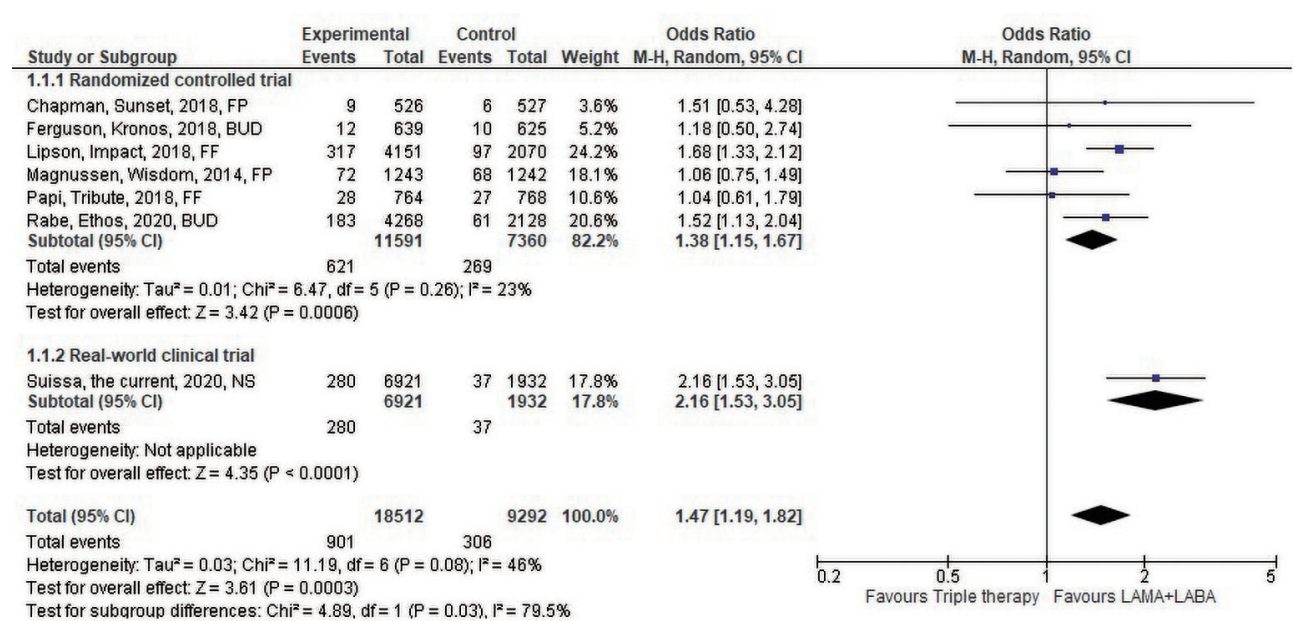

Figure 1 Forest plots for pneumonia frequency. The triple therapy versus the dual-bronchodilator therapy. The first author, study name if applicable, publication year, and a type of inhaled corticosteroids were shown on the left side. A random-model meta-analysis using MantelHaenszel (M-H) analysis was conducted using Review Manager ver. 5 (Cochrane, London, UK). A propensity score matched study was analyzed together with randomized controlled trials because a propensity score study mimics a randomized controlled trial. FP, fluticasone propionate; FF, fluticasone furoate; BUD, budesonide; NS, not specified.

using Review Manager version 5 (Cochrane, London, UK).

We eventually found six RCTs and one observational study (7-13). All of them were written in English language. Numbers of patients included in each study ranged from 1,053 to 8,853 with a median of 2,485 , and a total of 27,804 . The random-effect model meta-analysis revealed that the patients who were treated with the triple therapy had higher risk of pneumonia (odds ratio 1.47, 95\% CI, $1.19-1.82, \mathrm{P}<0.001 ; \mathrm{I}^{2}=46 \%, \mathrm{P}$ for heterogeneity $=0.08$; Figure 1). The impact of the triple therapy on the frequency of pneumonia was stronger in the real-world than expected from the RCTs (Figure 1) (7). The triple therapy also led to the increased risk of pneumonia based on a fixed-model sensitivity analysis (odds ratio $1.55,95 \%$ CI, 1.35-1.77, $\mathrm{P}<0.001 ; \mathrm{I}^{2}=46 \%$, P for heterogeneity $=0.08$ ).

Our data were consistent with previous meta-analyses that evaluated the impact of ICS on the pneumonias of COPD patients. Singh et al. reported a meta-analysis of 18 RCTs in 2009 (3). The included trials evaluated fluticasone propionate alone or budesonide alone or in the form of combination with LABA. They showed that ICS were associated with a significantly increased risk of pneumonia (relative risk, 1.60; 95\% CI, 1.33-1.92; $\mathrm{P}<0.001 ; \mathrm{I}^{2}=16 \%$ ) (3). In 2014, Kew et al. conducted an update meta-analysis incorporating 43 trials that evaluated fluticasone propionate and budesonide (4). The conclusion from Kew et al. matched to that from Singh et al. Our analysis had a few differences compared to these previous meta-analyses. First, we included recently published studies since 2014 (Figure 1). Second, one study adopted a new drug, fluticasone furoate. Third, we focused on the comparison between the dual bronchodilator therapy and the triple therapy. Finally, three RCTs adopted single-device triple therapy using a novel device. Despite these difference from the previous metaanalyses, adding ICS to other inhaler medication increased the risk of pneumonia (Figure 1) $(3,4)$. These consistent results are biologically plausible because corticosteroids are immunosuppressants. Regardless of the increased risk of pneumonia, we should mention that risk of all-cause death was lower in the triple therapy arm (OR $0.75,95 \% \mathrm{CI}$, $0.60-0.93, \mathrm{I}^{2}=0 \%, \mathrm{P}$ for heterogeneity $\left.=0.59\right)$, according to the random-model meta-analysis from the six RCTs.

A limitation is a moderate heterogeneity $\left(\mathrm{I}^{2}=46 \%\right)$, which was mainly explainable by study design (heterogeneity between RCT and real-world subgroups, $\mathrm{I}^{2}=79.5 \%$, $\mathrm{P}=0.03)$. Nonetheless, we believe that our data is trustful because both subgroups suggested significantly increased pneumonia risk in patients with triple therapy. Another limitation is that we could not detect high risk ICS type or patient characteristics leading to ICS-caused pneumonia.

Adding ICS on the dual-bronchodilator therapy decreased exacerbation and all-cause death, but increased pneumonia. Merits and demerits from the triple therapy should be well recognized. 


\section{Acknowledgments}

Funding: None.

\section{Footnote}

Provenance and Peer Review: This article was a standard submission to the journal. The article has undergone external peer review.

Conflicts of Interest: All authors have completed the ICMJE uniform disclosure form (available at https:// dx.doi.org/10.21037/jtd-20-1955). KW reports lecture fee from Novartis International, Boehringer Ingelheim, and AstraZeneca and research grant from KYORIN Pharmaceutical outside of the work. TK reports lecture fee from GlaxoSmithKline, Novartis International, Boehringer Ingelheim, and AstraZeneca outside of the work. NH has no conflicts of interest to declare.

Ethical Statement: The authors are accountable for all aspects of the work in ensuring that questions related to the accuracy or integrity of any part of the work are appropriately investigated and resolved.

Open Access Statement: This is an Open Access article distributed in accordance with the Creative Commons Attribution-NonCommercial-NoDerivs 4.0 International License (CC BY-NC-ND 4.0), which permits the noncommercial replication and distribution of the article with the strict proviso that no changes or edits are made and the original work is properly cited (including links to both the formal publication through the relevant DOI and the license). See: https://creativecommons.org/licenses/by-nc-nd/4.0/.

\section{References}

1. The Global Initiative for Chronic Obstructive Lung Disease. 2020 Global Strategy for Prevention, Diagnosis and Management of COPD. Available online: https:// goldcopd.org/gold-reports/. Accessed May 52020.

2. Horita N, Goto A, Shibata Y, et al. Long-acting muscarinic antagonist (LAMA) plus long-acting beta-agonist (LABA) versus LABA plus inhaled corticosteroid (ICS) for stable chronic obstructive pulmonary disease (COPD). Cochrane Database Syst Rev 2017;2:CD012066.

3. Singh S, Amin AV, Loke YK. Long-term use of inhaled corticosteroids and the risk of pneumonia in chronic obstructive pulmonary disease: a meta-analysis. Arch Intern Med 2009;169:219-29.

4. Kew KM, Seniukovich A. Inhaled steroids and risk of pneumonia for chronic obstructive pulmonary disease. Cochrane Database Syst Rev 2014;(3):CD010115.

5. Postma DS, Rabe KF. The Asthma-COPD Overlap Syndrome. N Engl J Med 2015;373:1241-9.

6. Johnstone J, Eurich DT, Majumdar SR, et al. Longterm morbidity and mortality after hospitalization with community-acquired pneumonia: a population-based cohort study. Medicine (Baltimore) 2008;87:329-34.

7. Suissa S, Dell'Aniello S, Ernst P. Comparative Effects of LAMA-LABA-ICS vs LAMA-LABA for COPD: Cohort Study in Real-World Clinical Practice. Chest 2020;157:846-55.

8. Chapman KR, Hurst JR, Frent SM, et al. Long-Term Triple Therapy De-escalation to Indacaterol/Glycopyrronium in Patients with Chronic Obstructive Pulmonary Disease (SUNSET): A Randomized, Double-Blind, Triple-Dummy Clinical Trial. Am J Respir Crit Care Med 2018;198:329-39.

9. Ferguson GT, Rabe KF, Martinez FJ, et al. Triple therapy with budesonide/glycopyrrolate/formoterol fumarate with co-suspension delivery technology versus dual therapies in chronic obstructive pulmonary disease (KRONOS): a double-blind, parallel-group, multicentre, phase 3 randomised controlled trial. Lancet Respir Med 2018;6:747-58.

10. Lipson DA, Barnhart F, Brealey N, et al. Once-Daily Single-Inhaler Triple versus Dual Therapy in Patients with COPD. N Engl J Med 2018;378:1671-80.

11. Magnussen H, Disse B, Rodriguez-Roisin R, et al. Withdrawal of inhaled glucocorticoids and exacerbations of COPD. N Engl J Med 2014;371:1285-94.

12. Papi A, Vestbo J, Fabbri L, et al. Extrafine inhaled triple therapy versus dual bronchodilator therapy in chronic obstructive pulmonary disease (TRIBUTE): a doubleblind, parallel group, randomised controlled trial. Lancet 2018;391:1076-84.

13. Rabe KF, Martinez FJ, Ferguson GT, et al. Triple Inhaled Therapy at Two Glucocorticoid Doses in Moderate-toVery-Severe COPD. N Engl J Med 2020;383:35-48.

Cite this article as: Watanabe K, Horita N, Kaneko T. The triple therapy for chronic obstructive pulmonary disease increases the risk of pneumonias compared to the dualbronchodilator therapy. J Thorac Dis 2021;13(10):6099-6101. doi: $10.21037 /$ jtd-20-1955 